This item was submitted to Loughborough's Research Repository by the author.

Items in Figshare are protected by copyright, with all rights reserved, unless otherwise indicated.

\title{
Marketing and the British bus industry
}

PLEASE CITE THE PUBLISHED VERSION

PUBLISHER

(C) Thomas Telford

LICENCE

CC BY-NC-ND 4.0

REPOSITORY RECORD

Enoch, Marcus P., and Stephen Potter. 2019. "Marketing and the British Bus Industry". figshare. https://hdl.handle.net/2134/3344. 
This item was submitted to Loughborough's Institutional Repository by the author and is made available under the following Creative Commons Licence conditions.

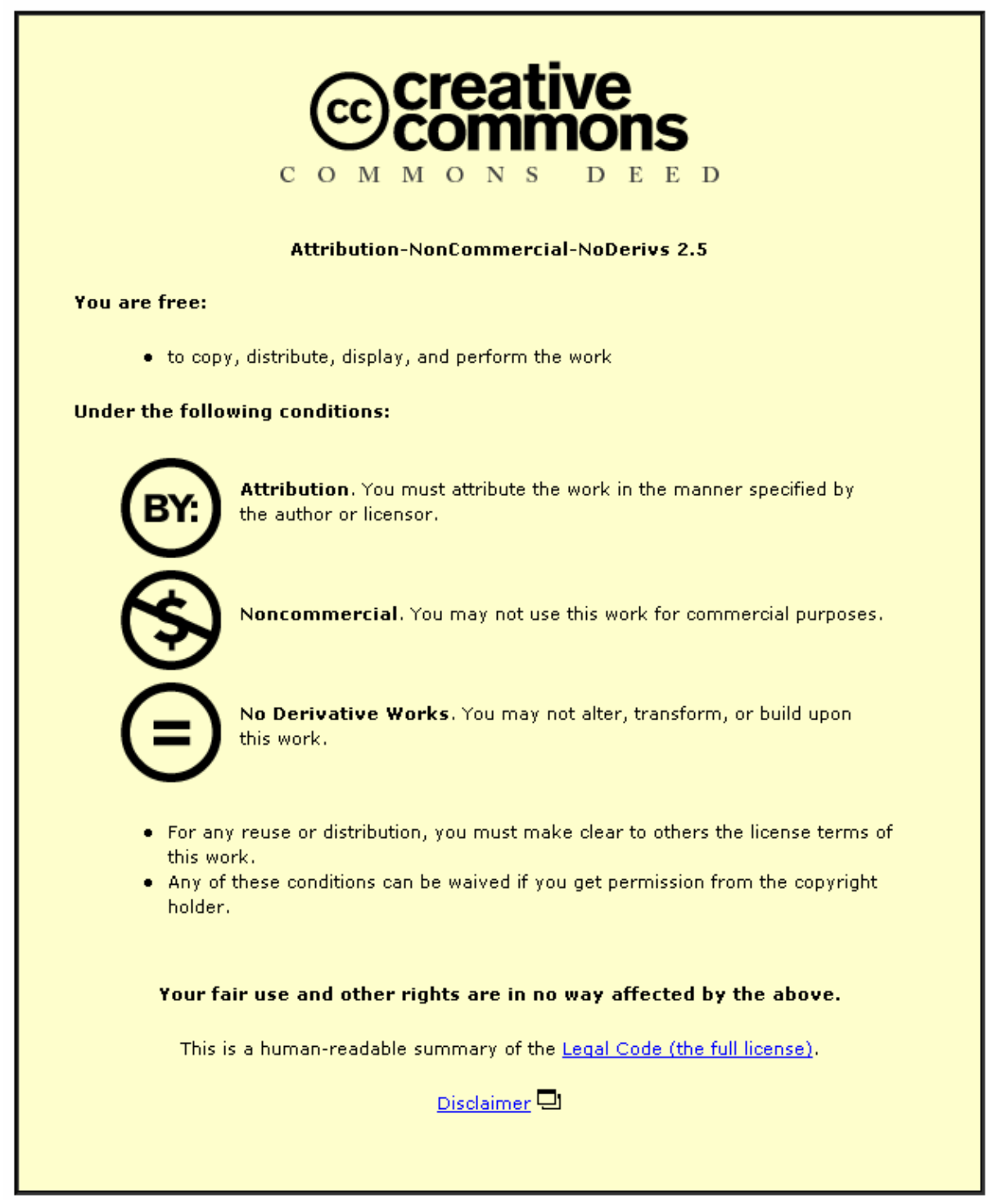

For the full text of this licence, please go to: http://creativecommons.org/licenses/by-nc-nd/2.5/ 


\title{
Marketing and the British Bus I ndustry
}

\author{
Dr Marcus Enoch ${ }^{*}$ and Dr Stephen Potter,
}

Centre for Technology Strategy,

The Open University.

\section{Summary}

The development of public transport services is a key element of all local sustainable transport strategies. Achieving modal switch from car users requires marketing systems be changed to identify and target suitable non-users of public transport, rather than just enlarging custom by existing users. However, in the public transport field, marketing is still essentially designed to only address the existing customer base. This is particularly acute among bus operators, who rarely even market effectively to their existing customer base, and have a poor image among car users.

This paper draws on the practical experience of some of the relatively few local bus operators and local authorities who have identified and won new markets, including modal shift from car. It looks at the sort of services they have developed, the marketing strategies adopted, and at how the stakeholders worked together. In addition, it provides hard evidence as to the benefits of marketing bus services properly, suggesting that patronage gains of around 5-7\% should be possible, even without major investment or legislative change.

In conclusion, seven key features of good practice are identified that need to be part of developing bus services to serve sustainable transport policies. These are CUSTOMISATION, CO-OPERATION, CLEAR VISION, CLARITY (TO THE USER), CORE MARKET, CULTURE, and CONTINUITY.

\footnotetext{
* Corresponding address is Dr Marcus Enoch, Centre for Technology Strategy, The Open University, Walton Hall, Milton Keynes, MK7 6AA. Tel: 01908 653970. Fax: 01908 654052. Email: m.p.enoch@open.ac.uk
} 


\section{Bus Services and Sustainable Transport Strategies}

The development of public transport services is a much-advocated policy to address transport's environmental impacts. A review and survey of the primary life cycle fuel consumption of a wide variety of vehicles (reported in Potter, 2000) indicates that public transport in peak hours uses less than $20 \%$ of the energy consumed by a single occupancy car (and most car commuting is single occupancy). For every peak hour car trip diverted to public transport, it is estimated that, even allowing for more public transport services needing to be operated, there is a net cut in $\mathrm{CO}_{2}$ emissions of just over 1 tonne per annum.

It is thus no surprise that the development of an attractive public transport service has featured widely in both national and local sustainable transport strategies. Although the development of new light rail networks has attracted much attention, for most towns and cities bus services remain the mainstay of local public transport. To develop these to address sustainable transport policies requires achieving modal shift from car users. This means marketing systems have to be changed to identify and target suitable non-users of public transport, rather than just enlarging custom by existing users. This crucial point is not often appreciated, with any growth in bus use being considered to contribute to 'sustainability'. Such growth makes no real contribution to a sustainable transport policy, and of itself simply generates further environmental impacts from the bus sector.

Achieving growth by winning trips from more environmentally-damaging modes is the name of the sustainability game, but for buses, marketing is only addresses the existing customer base. There is good news; the decline in bus use seems to have, at last, been halted and even reversed in some places. The bad news is that this is largely a result of increased use from existing user groups. Even marketing to this existing customer base is often rudimentary, and buses continue to have a poor image among car users. The core question this article poses is whether it is possible for bus services be effectively marketed so as to realise the considerable potential that they have to cut transport's environmental impacts.

\section{Marketing Buses}

In the public transport field, marketing is concerned with the selling of public transport services or journeys (AMA et al, 1994). This can be achieved by service design, promotion, branding, signage and information. However, it would seem that most bus company managers to not see such aspects as worthy of much attention. This has long been blamed on the peculiarities of bus operations - in particular because transport is a 'derived demand', bus services have a largely 'captive' market and because as a product bus travel is 'instantly perishable'. It is also often claimed that as passengers will catch the first bus (which may be old and dirty), it would be a waste of time and commercially disadvantageous to invest in a newer, cleaner vehicle or in training drivers to be more courteous. While some such factors may create particular difficulties, they cannot really justify poor quality bus 
services. This is because the success of companies such as Trent and Barton Buses and Brighton and Hove Bus and Coach Company has proved that where even some marketing lessons are applied, significant improvements in service quality - and in passenger numbers and revenue - have occurred.

TAS Partnership (1998) concurred, and stated that overall bus patronage growth of 5-7\% per annum should be possible, even without major investment or legislative change. It also came to some conclusions on the 'pay back' for such key features. Essentially, the benefits for every $£ 1$ spent on improvements were as follows:

- $\quad$ service simplification $\sim £ 3.50$ per pound spent;

- effective service promotion and branding $\sim £ 3.10$ per pound spent; and

- high quality signage and information, $\sim £ 2.80$ per pound spent.

Interestingly, 'hard' technology improvements scored much lower:

- $\quad$ bus stop improvements $\sim £ 2.20$ per pound spent;

- $\quad$ new buses $\sim £ 1.80$ per pound spent;

- bus priority measures $\sim £ 1.60$ per pound spent; and

- real time passenger information/automatic vehicle location equipment $\sim £ 1.20$ per pound spent.

Unfortunately, despite such compelling evidence, examples of promotion, branding, information and service simplifications have been the exception rather than the rule.

To determine why this is so, Paul Kevill of South Yorkshire Passenger Transport Executive conducted a series of interviews with bus industry managers (Kevill, 2000a; Kevill 2000b). He found that bus companies tended to operate within a public service/local government culture, and were almost run along military lines - being very hierarchical, and with staff strictly controlled and not really trusted. This was summed up as an "if you're 10p short, you're dead" type of attitude. He also detected a 'bus spotter' mentality, with bus managers more fixated with the kit than the customer - i.e. bus operators tend to be product rather than market driven. Overall, he felt the industry saw the customer as a nuisance. Kevill found that the term 'marketing' was widely misunderstood, and taken to mean advertising and promotion rather than the whole concept of providing goods or services to meet consumer needs. Finally, he found that the basic failing of the bus product is that it "doesn't do what it says on the tin”. Put simply, the main problem is that the product doesn't work properly.

It can be enlightening to use a classic marketing approach used universally in business and explore its consequences for bus services. This is the 'marketing mix', which is divided into four parts or the four 'P's: product, price, promotion, and place. To that can be added a fifth 'P', people.

\section{The bus product}

The bus product is the bus service that delivers people from where they are to where they want to go. It is not merely a journey or a transaction. Ideally, public transport needs to be as simple to use as 
possible, and that means removing as many barriers as possible that currently dissuade people from using it.

One key factor behind good practice bus operations is that they have a fair idea of what their customers want - i.e. they research their market. And, once they have introduced their improvements they continue to carry out research exercises to see if and why these have worked or not. For example, before implementing its Gold Service routes, First Aberdeen found that the key factors that customers wanted were reliable services, quality vehicles, and quality staff, at affordable prices (Mair, 1998). Trent and Barton Buses is another bus company that frequently asks its passengers what they want through independent market research exercises, and aims to achieve this through a stringent quality control regime backed up by a Customer Charter that includes a 'money back for any reason' guarantee. (BIA, 1999).

Typically, regular passengers say they want cheaper fares for riding on buses, while those who bus operators want to attract onto their services generally put reliability and effective frequency to the top of the list (Kevill, 2000b; TAS Partnership, 1998). This has important implications. Key factors that satisfy existing users are different from those that attract motorists. Work by Steer Davies Gleave for Transport 2000 identified five key barriers preventing motorists using buses: inadequate networks, a lack of information, longer journey time, access difficulties, and general concerns that public transport is unusable (SDG, 1997). A bus operator that majors on the things that existing users value would miss out on these additional factors that would be needed to effect modal shift.

According to Mark Fowles of Nottingham City Transport, (Fowles, 1998), "Effective marketing is about defining needs, wants, desires and barriers, and about targeting the market”. The bus industry has become entrenched in the "if we provide a service people will use it" attitude. Bus services are no different to any other product: they must be sold by the most appropriate means. Effective marketing is about giving comfort and allaying the fears a new customer may have of the service. He emphasised that to the non-user even the most basic aspects of the system can appear as a barrier.

\section{Defining the product}

To satisfying both existing customers and growing by modal shift requires a:

- A pleasant waiting environment;

- Good reliability;

- An easy to understand network;

- An easy to understand ticketing structure;

- Easily accessible vehicles to those with heavy shopping, prams and pushchairs, and wheelchairs;

- A direct service with easy interchange;

- A frequent service;

- Good value for money; 
- Friendly and helpful staff; and

- Comfortable, clean, well heated and ventilated vehicles.

While many of the above criteria are self-evident (though not always to bus managers it would seem), others are worthy of further comment. These particularly apply to the 'modal shifter' factors.

\section{An easy to understand network}

One particular area of concern, especially since the 'deregulation' and privatisation of the bus industry in the 1980s, has been the lack of good quality passenger information - i.e. and easy to understand network. Passenger information is not promotion - it is a part of the product. On most other products, such basic information explaining how it should be used would appear as instructions. If people are to use public transport, they need to be able to obtain and understand information on what journeys or routes are available, where and when services are operated, and where and how they pay to use it.

In the provision of bus services, this is often not the case. Instead, bus operators typically say that, as $80 \%$ of their passengers are regular users and know the information they need, any extra information would not really be worth providing. There are two reasons why this is worrying. Firstly, the $80 \%$ figure typically refers to passengers on any given bus load. This means that the $20 \%$ of passengers who are not regular passengers change each bus load. The actual number of infrequent users is high, but they do not use buses much. Indeed, there could easily be more irregular users over the course of a week or so than regular users. The irregular fringe user, who is the crucial target group for growth, is thus disadvantaged.

Good information cannot, of course, compensate for bad network design. Networks need to be understandable, with simple routes, simple timetables, and simple fares. They should also be consistent. To do this, from planning to arrival, people need to be helped to consider buses, helped to plan in advance and helped at the stop. Also, the bus should be clearly labelled. Essentially, information everywhere should be available, informative, comprehensible, attractive and up-to-date (Smith, 1998).

\section{Simplifying the product}

Of course many of these criteria are strongly linked. Simplifying the network for example, tends to be easier to understand, and usually leads to improved frequencies, and more direct services, while passenger information becomes less complicated. Improved frequencies also help mask some unreliable services, reduce the time spent waiting at the stop, and speed up journey times. More comfortable vehicles and friendly staff allow passengers to feel they are getting value for money. Unfortunately, most bus services in Britain currently fail to deliver these, although there have been slow improvements.

As Peter Huntley of consultant The TAS Partnership points out (LTT, 1997a), "If you make the system simple and easy to use, run often enough to just ‘turn up' for, and maintain stability, you don't need publicity”. "Car users are not interested in local authority 'telephone books' listing every obscure 
and little bus service", he continues. "Get the product right - simple, regular, direct, stable - and you can forget about publicity”. Huntley cited Manchester Metrolink as the most successful example of public transport attracting car users despite very little service information. However, for bus services his contention may be overly optimistic. But it is certainly true that the simpler the service, the less taxing the information requirements (and vice versa!) For example, if a high frequency service (ten minutes or less) could be operated throughout the day, probably the only information required would be details of the route and fares, the time of the first and last bus, and the time interval between each bus.

\section{Concentrating resources and serving the core market}

Morgan (1995) noted that "any successful volume business will tell you that to succeed in a competitive world you must identify your market and design your product to meet or exceed the requirements of your customers. You will also be told never to compromise your product by trying to appeal to marginal or fringe markets. Leave niche markets to those best geared up to serve them - you concentrate on your core market - dilute your product at your certain peril”. He continued that the bus industry had tended to follow the opposite approach - whereby the operator tried to offend as few people as possible. Thus, a few vocal opponents would render any changes redundant - hence the importance of market research in finding out what the silent majority wants. Therefore, "where operators have re-designed their products to meet the specific requirements of the core market - the majority - organic growth has resulted. If we make our services attractive to the vast majority, demand will increase and we need not worry about marginal demand - our future depends on the core".

\section{Branding}

Branding works at a number of levels and is now a key element in the success of almost any business. Indeed for many companies the value of the brand exceeds that of their tangible assets. At a company level, branding is used to bond users with their products - witness Levi Jeans, Coca-Cola, and indeed car manufacturers. People identify these products as part of their personality, and companies devote considerable time, resources and money to developing and defending successful branding.

Bus companies simply cannot use, as yet, branding at this level, but the tactical use of branding at the service level can yield valuable results. One visible sign of concentrating resources and of simplifying the service to make them easier for the public to understand, is to 'brand' particular routes. In practice, this has not often occurred due to operational flexibility requirements - using buses of the same colour makes it easier to replace vehicles should they need repairing, and to park in the depot.

In other cases, the application of branding meanwhile has not been fully understood, and any positive message has been lost. Kevill (2000b) noted that in Sheffield, buses of South Yorkshire Transport were painted red and yellow to become 'Mainline' - where frequencies of ten minutes were guaranteed. But, for some reason eventually all SYT buses were branded as 'Mainline', despite several routes not running at ten minute frequencies, rather diminishing the brand. Also in Sheffield, some buses were branded to specific routes using vinyl strips down the side of the bus to explain which 
stops they served. Unfortunately, these were not always parked correctly at the depot, meaning that unbranded buses were sometimes used on branded routes (not ideal), or route branded buses were used on unbranded routes (extremely confusing for the passenger) (Kevill, 2000b).

Where buses have been route branded though, especially as part of a whole package involving making routes easier to understand, results have been impressive. For example, TAS Partnership (2000) reported that Brighton and Hove Bus and Coach Company achieved growth of $8 \%$ a year on its five core branded 'Metro' routes, the FirstGlasgow Overland network gained 4\% more passengers a year (after a long period of decline). Patronage on Travel West Midlands Line 33, Superline and Primeline Showcase routes rose by $28 \%, 18 \%$ and $5 \%$ respectively ${ }^{1}$.

\section{Public transport pricing}

Pricing is another area where the bus industry has not tended to be marketing oriented. Instead of charging what the market will bear, as in other sectors such as in the retail, airline or railway industry, pricing has traditionally been based on mileage travelled. This has frequently led to ridiculous cases such as one in Milton Keynes. Here, three years ago it was possible to travel from Central Milton Keynes to Bletchley in around 20 minutes for 80p. But, if another bus was taken that travelled around several estates the trip between the same start and end points the journey would take twice the time and cost $£ 1.35$. Thus, passengers were paying nearly twice as much to sit on a bus that took twice as long to complete the journey - and this type of example is not uncommon.

There is also a misconception that customers are fixated on price. The issue is more one of value for money - "the price is too much for the service we get", rather than the actual fare being too expensive.. It is also interesting to note that in other sectors such as telephones, electricity, gas etc., those with no choice pay far more (through payphones and meters) per unit than better off people. This sort of market segmentation is virtually unknown in the bus industry, although from a marketing point of view it may make more sense to offer special discounts to those who would otherwise use the car.

\section{Customer ticketing requirements}

Obviously, value for money, ease of purchase, flexibility of use, simplicity, user friendliness etc. are all very strongly related. Value is related partly to price, but also to the added value of other benefits as a reward for committing money in advance, notably convenience of purchase and flexibility of use. The problem is, that bus operators tend to feel that 'carnet' style tickets - where customers buy a multiple pack of tickets in advance for a slightly discounted price - somehow lead to revenue leakage, especially if these are transferable. Thus, occasional users face buying tickets on board the bus. This

1 'Showcase' route Line 33 operates between Birmingham city centre, Kingstanding and Pheasey, 'Superline' links Coventry city centre and Foleshill, and 'Primeline' connects Walsall and Bloxwich. The services began operating in February 1997, June 1998 and August 1998 respectively. 
can be a very stressful experience, as well as being frustrating for the driver, and time consuming for everybody. Often passengers are required to tender the 'exact fare', and even where change is usually offered, this only applies if the company provides each driver with an adequate 'float'. Otherwise further embarrassment and delay is encountered as change is sought from other passengers etc..

Logically therefore, buying tickets off the bus in advance would benefit the customer and driver, reduce journey times, and provide operators with cash up front. Such an approach is common practice across much of Europe, but although off-bus sales occur in London, where customers can buy Travelcards (and now 'Saver Six' bus Carnets) at certain shops and newsagents, it is not so common in other areas. This is despite public transport patronage in London increasing by $16 \%$ on the introduction of Travelcards in 1982, and a 36\% increase experienced in Paris when the similar 'Carte Orange' was launched seven years earlier (EC, 1996).

The majority of customers make the same journey on a regular basis but not on five days a week. There is also a desire for transfer journeys without the need to buy another ticket, and demand for transferability of pre-paid tickets between passengers and within the family. Again though, with a few exceptions such as Brighton and Hove Bus and Coach Company, operators have been very slow to address this.

Flexibility of use also applies to the area of tickets being valid on services run by a number of different operators. Outside of London and Passenger Transport Executive areas though, competition law as enforced by the Office of Fair Trading means that even for competing operators to accept each other's tickets is fraught with legal difficulties.

\section{Operator requirements}

The needs of the operator have supposedly focused on the ability to maximise revenue to develop customer loyalty, both to public transport in general and the bus operator in particular. In reality, while the first part of the statement is true, in the British case the rest as a rule is not. This is a sentiment echoed by Melvyn Hopwood, the head of communications at Trent and Barton Buses who said that across the industry on market pricing and loyalty cards "we are rubbish” (Hopwood, 2000).

As noted earlier, market-based pricing in the bus industry is almost unheard of, never mind practised in complete contrast to the rail sector. One exception is in Manchester, where the local Stagecoach subsidiary has segmented the market by socio-economic group, and by time of day: For example, certain services have been targeted at night clubs, with posters of a style appropriate for pubs and clubs. Another segment is the University corridor of Wilmslow Road. Here Low cost "Magic Bus" branded services - using old buses - have actually grown faster than quality services with new vehicles (Colson, 1998). Other operator needs are to exploit sales outlets, and speedy and efficient operation both enhanced by selling tickets before passengers board the bus.

Two more concepts that have not really caught on in the bus industry, are 'added value' and 'loyalty cards'. Added value allows companies to charge a higher price justified by an improved level of service, without costing the provider much more money, while rewards for loyalty aim to persuade 
customers to stick with the product they use. Almost a combination of these ideas, popular among supermarkets, is the loyalty card approach. Here, customers can claim either gifts or cash back after spending more than a set amount of money. These cards now have the added benefit of being able to record exactly what products each customer buys, together with general information about the customer, providing an extremely powerful database from which marketing activity can be targeted later.

However, despite these advances, even simple examples of added value in the public transport industry are rare. Rover tickets issued by operator Southern Vectis on the Isle of Wight, give discount at almost 20 key places of interest, while various bus operators have offered free newspapers to passengers at some time or other (Southern Vectis, 1999). Arriva Scotland West, launched the first bus-based loyalty card in Scotland in response to competition from smaller operators. Similar in design to those used by supermarkets, 'points' recorded by a metallic strip on the card can later be redeemed against free travel vouchers, money-off vouchers at a local supermarket, or a donation to charity. The scheme boosted patronage some $15 \%$, some $7 \%$ above similar services without a loyalty card (BIA, 1999).

With the recent developments in electronic cards, options of how passengers pay for public transport have correspondingly multiplied. The simplest electronic cards contain a fixed value or number of trips which decreases with use. More complex 'smart cards' contain memories that can differentiate fares by distance travelled or by time of day. This allows for precise allocations of revenue to various operators, while the data can also help service provision become more responsive to customer needs (EC, 1996). As yet, while various types of smart cards have been in use for many years overseas, only a few operators in the UK, such as Arriva The Shire in conjunction with Hertfordshire County Council, have taken the plunge with the various new technologies on offer.

\section{Place}

'Place' refers to the distribution of the product, the access to it - how people get hold and pay for it. Complexity is again a barrier here, particularly when compared to car use. For instance, certain buses only serve certain areas at certain times, and quite often these are irregular throughout the day. Similarly, fare information is often almost impossible to understand. A comparison may be made to shops, which like buses have busy periods and quiet periods, but they tend to stay open between fixed times, and are all the time striving to justify extending their opening hours as far as possible.

Place also exerts a considerable impact on the composition of the market, and therefore what type of services are needed. In bus marketing terms, every locality is unique (in terms of wealth, culture, density, car ownership levels, road structure etc.), and thus requires a tailored approach to developing provision. Market research is crucial in assessing the salient features of this uniqueness, and in developing a suitable service to address these. When considering how best to serve an area, market research is needed to ascertain the needs of local people, and to develop a service that will meet those needs as closely as possible. And, operators should strive to simplify services and provide sufficient information to make it easy for people to understand and to use. 


\section{Promotion}

Although promotion is closely related to passenger information, it has a slightly different emphasis that focuses on the USP - the Unique Selling Proposition. This could be that "using the bus is cheaper than the car”, “buses are every ten minutes”, or “for a limited time accompanied kids travel free”.

Obviously a product should only be promoted when it is worth promoting - in the words of Professor John Hibbs of the University of Central England Business School "you can only advertise a poor product once. After that it is dead”. Perhaps as a result of this combined with the public service ethos and operational culture, bus services have not been widely advertised, at least in the UK.

When boarding a bus nearly every single message or warning is either legal or technical and of irrelevance to the passenger (e.g. "the capacity of this bus is 72 sitting, 8 standing”), or negative e.g. “do not speak to the driver", "this bus only accepts exact change”, or "do not stand forward of this notice”. This has now extended to notices discouraging the use of mobile phones and eating. Compare this to a pub or a shop, where just about every customer sees sign extols the value of a product or product range to the customer. For example, "special offer on draught bitter", or "two cans of beans for the price of one”, or is positive "Visa and Switch accepted here”, and "please ask if you need help" (Kevill, 2000b).

To best promote public transport, the product first has to work properly. Once this is achieved, a useful method is to promote the positive features identified in the market research, that reflect the desires of the existing and potential market. So, if people want more frequent buses, provide more services and advertise buses "every ten minutes". Or, for example, if people want cheaper fares, then cut the fares or give vouchers for buying season tickets, and publicise "buy one week travel, get one week free”.

Success also depends on how such messages are targeted - if young people are being encouraged, the material should reflect that and be made available where young people are likely to see it or pick it up. Finally, good relations should be sought with the local media, local politicians and the general public.

\section{People}

The people aspect is especially important in the service sector, which includes public transport provision. While some companies have, or are beginning to introduce such innovations, quite often efforts to improve driver friendliness and helpfulness somehow get diluted and decline over time. Despite this, there are a number of public transport operators where the importance of friendly and helpful staff is recognised.

In any service industry, people are a crucial part of the product. The experience that many people have of public transport is that this is not true. Therefore the operator needs to adapt a customer perspective, rather than the operator-led culture that currently predominates. This is not to deny that drivers need some level of control when serving the customer, to allow them sufficient flexibility to deal with passengers properly. Staff also need be involved in what the company is trying to achieve. At the 
moment for the most part they are not, and thus have no real stake in how well the company performs. This is especially important, as for the most part bus drivers cannot really be supervised once on the road and meeting the public. Training should also be a major priority, especially for those who must interact with the public - e.g. drivers, bus station staff, ticket sellers and information providers.

\section{Conclusions and recommendations}

Marketing is a profession that uses snappy acronyms and aide memoirs to drive home its techniques. Witness the four 'P's: product, price, promotion, and place (plus our fifth crucial ' $\mathrm{P}$ ' of people). A paper on bus service marketing to serve sustainable transport policy objectives could hardly be complete without providing the reader with something similar. Indeed, we have chosen a term so corny that you are hardly likely to forget it. This, of course, is done in the name of effective marketing.

The starting point is that improvements in public transport provision can only be brought about if a package of measures is introduced that ideally including car restraint as well as bus priority, and high service quality. To emphasise this need for a package of co-ordinated actions, this review summarises best practice in marketing, ticketing and passenger information as a checklist of seven ' $\mathrm{Cs}$ '. To take this nautical pun to its logical conclusion, any operator or public authority charged with the responsibility of developing a network of public transport operations should ensure that they voyage across all the seven Cs, (we said this would be memorably corny). This voyage requires the recognition of:

- CUSTOMISATION - "know your market" - every situation is unique, and the solutions that work best are fully dependent on local needs, the level of available resources, and the enthusiasm of each involved partner;

- CO-OPERATION - roles and responsibilities of each party must be clear and unequivocable consortia work best when all the key players, including the user, are involved from the earliest possible moment in the process so co-ordination of the measures being introduced is vital; and that

- CLEAR VISION - shared by all the partners, illustrating what public transport should be (and will be) like in the area.

- CLARITY (TO THE USER) - simplifying all elements in the process of catching a bus - in finding out initial information about what travel options are available and about how to use it (when and where to catch it, how and where to buy tickets), and then about actually using it.

- CORE MARKET - services should be designed to meet the needs of the majority on that particular route. Where new investment is available, resources should be concentrated along a corridor or route, so that passengers are aware of a 'step change' in the quality of service being offered; and

- CULTURE - system should be customer focused. Good marketing is critical if the full benefits of a partnership are to be realised. 
- CONTINUITY - stability of services is important. Change should only occur where absolutely necessary.

Bon voyage!

\section{References}

Association of Metropolitan Authorities, Association of County Councils, Association of District Councils, Convention of Scottish Local Authorities (1994) Ticket to ride: Policies for better buses, AMA, London.

Balcombe R and Vance C (1997) Information for bus passengers: a study of needs and priorities, Transport Research Report 330, TRL, Crowthorne, Berks.

Bus Industry Awards (1999) Guide to the 1999 Bus Industry Awards, November, London.

Cole C (2000) Telephone interview, March.

Colson B (1998) Public transport information in Manchester, Presented at a JOULE-THERMIE conference entitled Promoting travel by bus - making publicity pay, ETSU, 15 September, Birmingham.

DETR (1999a) Focus on Public Transport, Great Britain 1999 Edition, Government Statistical Service, The Stationery Office, London, February.

DETR (1999b) From Workhorse to Thoroughbred: A Better Role for Bus Travel, Crown Copyright, London, March.

Enoch M P (1998) Bus-Based Best-Practice and Urban Transport Emissions, Ph.D. Thesis, Energy and Environment Research Unit, The Open University, Milton Keynes, February.

European Commission (1996) The citizens network: Fulfilling the potential of public passenger transport in Europe, European Commission Green Paper, Brussels.

Forster A (2000) Can simplified urban bus networks encourage the motorists to step aboard?, Transit, Issue 123, 14 January, pp.10-11.

Fowles M (1998) Identifying barriers and meeting aspirations, Presented at a JOULE-THERMIE conference entitled Promoting travel by bus - making publicity pay, ETSU, 15 September, Birmingham.

French R (2000) Interview in Brighton, February.

Friends of the Earth (1997) The bus stops here: How bus stop information in the West Midlands compares with other regions, Birmingham FoE, October.

Hopwood M (2000) Telephone interview, Trent and Barton Buses, 9 February. 
Kevill P (2000a) The implications of bus operator paradigms for local government intervention in transport markets, Presented at $32^{\text {nd }}$ Annual Universities Transport Study Group, 5-7 January, University of Liverpool.

Kevill P (2000b) Interview in Sheffield, February.

Local Transport Today (1997a) Can bus services really be improved enough to encourage modal shift?, News Extra, 11 September 1997, pp.9.

Local Transport Today (1997b) Bus Industry Awards help show what partnerships can deliver, News Extra, 20 November 1997, pp.9.

Mair G (1998) GOLD service, Presented to a Local Transport Today/TAS Partnership Conference: The role of buses in the new transport policy environment, London, 23 June.

McQuillan E (2000), Personal communication, 28 February, Commercial manager, Southern Vectis, Isle of Wight.

Morgan I (1995) Public transport - private profit? The bus operator's perspective, 26th Annual Public Transport Symposium, University of Newcastle, 4-6 April.

Moffatt K (1998) Innovative approaches to service integration and through ticketing, Presented at a JOULE-THERMIE conference entitled Promoting travel by bus - making publicity pay, ETSU, 15 September, Birmingham.

Potter, Stephen (2000): Travelling Light, Theme 2 of T172 Working with Our Environment: Technology for a Sustainable Future, Open University Press, Milton Keynes

Simmonds S (2000) Information by email, Milton Keynes Council, February.

Smith R (1998) The role of passenger information, and how AVL can help, Presented to a Local Transport Today/TAS Partnership Conference: The role of buses in the new transport policy environment, London, 23 June.

Southern Vectis (1999) 'Bus guide' and 'Getting around the Isle of Wight', 23 May - 25 September, Southern Vectis, Isle of Wight.

Steer Davies Gleave (1997) A quality blueprint for public transport, Transport 2000, London.

TAS Partnership (1997) Quality Bus Partnerships in the Bus Industry: A Survey and Review, The TAS Partnership, Preston, September.

TAS Partnership (1998) Modal shift: Essential components of success, Presented to a Local Transport Today/TAS Partnership Conference: The role of buses in the new transport policy environment, London, 23 June.

TAS Partnership (1999) Quality Bus Partnerships: A Survey and Analysis, The TAS Partnership, Preston, June. 
TAS Partnership (2000) (ed. Enoch M P) ‘Quality bus infrastructure: A manual and guide.’. Prepared for the DETR, Landor Publishing Ltd, London.

UITP (1996) Ticketing for the customer, UITP Report, Brussels.

Whitley D (1998) Cost effective information provision, Presented at a JOULE-THERMIE conference entitled Promoting travel by bus - making publicity pay, ETSU, 15 September, Birmingham. 